\title{
Las distintas y olvidadas
}

\author{
Filósofas de la Modernidad \\ temprana y la llustración
}

PLATAS BENITEZ, Viridiana; TOLEDO MARÍN, Leonel.

México: Universidad Veracruzana, Biblioteca Digital de Humanidades, 2014. p. 125.

El libro que nos proponemos reseñar se titula "Filósofas de la Modernidad temprana y la llustración", coordinada por los doctores en Filosofía mexicanos Viridiana Platas' y Leone Toledo Marín. ${ }^{2}$ La obra, editada por la Universidad Autónoma de México y reproducida digitalmente por la Universidad Veracruzana, cuenta con una introducción y nueve capítulos.

Leyéndolo, podemos ver que es un libro de historia de la filosofía, escrito por filósofos especializados en la Modernidad y la llustración. El objetivo de la obra es mostrar el pensamiento de algunas filósofas de la Modernidad que actuaron y produjeron entre los siglos XVII y XVIII principalmente en Francia e Inglaterra. México país donde se origina el estudio, también estó representado en un capítulo referido a Sor Juana Inés de la Cruz, como representante de esa modernidad temprana hispánica y barroca.

La modernidad carece de estudios específicos en torno al pensamiento femenino producido durante esta época, donde la razón y la virtud se sustentaban en los nuevos valores planteados por las revoluciones liberales y los cambios sociales, económicos y políticos. Estudios sobre la modernidad y la llustración hay muchos, donde la filosofía en simbiosis con la historia hace conjunción para explicar una época proficua de pensamiento y descubrimientos. La razón y los valores de libertad e igualdad enarbolaron varios pabellones revolucionarios y rindieron culto al valor transformador y liberador del hombre. Sin embargo, pocas veces nos hemos preguntado qué rol jugaron las mujeres en esos ámbitos de discusión y reflexión continua. Esas mujeres, distintas para su época porque salían de los parámetros comunes y eludían los controles y valores culturales transmitidos por una cultura conservadora que las pretendía sumisas y recluidas, también pensaron y contribuyeron a la construcción de esos principios y conocimientos filosóficos en boga.

El libro a reseñar nos parece que resume el aspecto filosófico, pero hace un aporte sustancial a la historia de las mujeres en tanto es historia biográfica de las mujeres en su ámbito privado y público, pero también se utiliza a la microhistoria, ya que apunta al desarrollo particular de los aspectos intelectuales de las protagonistas elegidas.

"Filósofas de la Modernidad temprana y la llustración", es un libro de historia de la filosofía pero también de historia cultural, de historia de las mujeres y de historia del feminismo en su etapa primaria. Es un intento por descubrir a esas mujeres olvidadas por la historia cultural, que a lo sumo se cree actuaron como propagadoras de los filósofos más conocidos. Es un buen intento por sacar de la periferia académica e intelectual a pensadoras que no solo tuvieron ideas propias, sino que construyeron, junto con los autores clásicos, el andamiaje cultual e ideológico de una época clave en la historia del pensamiento occidental. También es importante resaltar el valor que tiene el libro para desentrañar los orígenes de un feminismo primario, donde las filósofas comienzan a plantear, a la luz de las revoluciones liberales, las primeras reivindicaciones en torno a la igualdad de derechos entre hombres y mujeres. Muchas de ellas lucharon contra las contradicciones y prejuicios de una época imbuida de liberalismo 
y derechos, pero de escaso reconocimiento a las minorías tradicionales como eran consideradas las propias mujeres. Algunas firmaron sus trabajos con los apellidos de sus esposos, otras escribían con otros filósofos que se llevaban e crédito, algunas fueron ejecutadas por sus ideas y otras reconocidas póstumamente. En el mejor de los casos, fueron consideradas seguidoras de un filósofo, pero no reconocidas como las que producían conocimiento.

Cada uno de los nueve capítulos se refiere a una filósofa en particular. En el capítulo uno de Laura Benítez Grobet, del Instituto de Investigaciones Filosóficas de la UNAM, titulado "Algunas reflexiones sobre el filosofar de las mujeres en la modernidad temprana", se describe un estado de situación acerca de la historia de las mujeres filósofas de la modernidad y cómo la historia de la filosofía las ha ignorado al menos hasta el siglo XX. Las temáticas de las mujeres de los siglos XVII y XVIII fueron variadas en materia filosófica ya que giraron en torno a varios temas. Expresa la autora: "Hubo varias mujeres en Francia e Inglaterra que escribieron sobre educación y derechos de la mujer, pero también sobre casualidad, escepticismo y conocimiento del mundo externo". ${ }^{3}$

Dentro de ese rescate que hace Benítez Grobet está el de Sor Juana Inés de la Cruz. Una religiosa que pensó en la posibilidad de aplica el conocimiento para la obtención de saberes hasta ese momento sepultados en la oscuridad. Además, ya tuvo un mérito: ser mujer en una colonia como la Nueva España del siglo XVII.

Zenia Yébenes Escardó analiza el pensamiento místico de Madame Guyón. Esta filósofa francesa del siglo XVII vinculada a la "ciencia experimental" o misticismo, reafirma su creencia en Dios y la trascendencia de éste en un tiempo donde comienzan a plantearse proyectos antropocéntricos donde la razón y la ciencia tienen un valor superior al trascendental. Sin embargo, Madame Guyón no discute la existencia de Dios, sino que lo considera como meta a alcanzar. Sin embargo, no descarta el uso de la razón y los métodos ilustrados para llegar a su conocimiento. Madame Guyón creía haber sido iluminada por Dios, al punto tal que sus acciones eran las de Dios. El sustento de esta concepción estaba en la experiencia mística de quien la vivía. Esta idea trasciende la fe y los formalismos circunscriptos en los dogmas religiosos. Para ella la práctica del "amor puro" era la forma de conocer a Dios, lejos de la mediación con los dogmas religiosos. Fue también una crítica de la situación de la mujer.
Parte de la base de que la culpa de la degradación femenina proviene de las propias madres que tratan mal a sus hijas y las crían para ser sumisas a los hombres.

El autor Javier Luna Leal, en otro de los capítulos, escribe sobre la correspondencia que mantuvieron Descartes con Elízabeth de Bohemia. En este trabajo se maneja como principal recurso la idea de que Elízabeth de Bohemia no solo tuvo a Descartes como maestro, sino que sus misivas, que tenían como principa recurso de indagación el método cartesiano interrogativo, constituyeron una verdadera forma de lograr la construcción y reformulación de pensamiento filosófico. A sus preguntas, Elízabeth agregaba comentarios o reflexiones que conducían a ampliar el razonamiento que hiciera el creador del método científico. El autor, rescata pues, el valor que tienen esas notas y cartas que se intercambiaron ambos como verdadero recurso de construcción intelectual.

Zuraya Monroy Nasr hace un análisis de la crítica de Margaret Cavendish a la filosofía experimental. Esta mujer, nacida en la Inglaterra de mediados del XVII, estudió profundamente a los filósofos más reconocidos de su tiempo para luego hacer una serie de críticas a sus observaciones y planteamientos. De esta manera, Cavendish llega a la conclusión de que naturaleza y conocimiento están integrados, concibiendo una idea monista en el cual confluyen lo espiritual con lo material. El método de trabajo planteado por Cavendish también se separa del dominante. Los filósofos experimentales partían de la observación y experimentación como forma de lograr certezas y verdades. Para ello, el uso de instrumentos técnicos era esencial Cavendish. en cambio, plantea que, además de eso, la filosofía debía basarse en supuestos teóricos o "especulativos" que lleven a la búsqueda de conocimientos. Esto la llevó a posturas que explicaban la situación de la mujer. Su crítica a la filosofía mecanicista la llevó a considerar que esta era una construcción de los hombres, mientras que las mujeres debían plantear un universo más orgánico y vitalista.

José Robles García analiza a Catharine Trotter Cockburn y su defensa de las ideas de John Locke. Al comenzar la lectura, podríamos pensar que se trata de una simple defensora de un pensador. Es decir, veríamos a una mujer en la periferia del pensamiento de un consagrado filósofo de la modernidad británica. Sin embargo, como seguidora que fue de Locke, Catharine Trotter Cockburn se transformó en una difusora de las ideas lockeanas, basadas en el 
pensamiento racional como forma de lograr el conocimiento alejados del dogmatismo religioso. Tomando al filósofo inglés, Trotter Cockburn explica que los valores no fueron creados por Dios, sino por la misma naturaleza humana, la cual es perfeccionada constantemente mediante el uso de la razón.

Viridiana Platas Benitez realiza un estudio sobre Damaris Cudworth. Es un aporte enriquecedor sobre la reflexión de esta filósofa inglesa del siglo XVII; se constata el valor que para ella tenía la razón y la libertad como medios para alcanzar la virtud. Para lograrlos, la educación era un medio fundamental en transmitirlos.

Carmen Silva plantea en su capítulo el análisis de Émilie du Châtelet, iniciándose así el estudio de las filósofas del siglo XVIII. La autora analiza con gran amplitud la vida y el pensamiento de esta filósofa ilustrada que vivió siempre bajo la sombra de Voltaire. Sin embargo, la historia de la filosofía olvida los enormes aportes de esta mujer a la construcción de la filosofía experimental y las traducciones de la obra de Newton al francés, lo que hizo más conocido el pensamiento de ese filósofo británico. Este trabajo no se limitó solo a la traducción textual, sino que hizo un estudio preliminar de su obra, lo que la hacía una conocedora de las teorías newtonianas.

Donovan Hernández Castellanos nos ubica en la Francia revolucionaria donde analiza la acción de Théorigne de Méricourt. Esta revolucionaria francesa plantea la defensa de los valores revolucionarios y la obtención de derechos políticos para las mujeres, además de defender la participación activa de la mujer en la revolución directa. Por eso, Méricourt llama a las mujeres a prepararse para la guerra civil y luchar a la par de los hombres en defensa de la república recién lograda. De esta manera las mujeres se igualarían a los hombres.

El último capítulo escrito por Isaac Moctezuma Perea busca interpretar aspectos filosóficos de Mary Wollstonecraft. El análisis se basa en lo que el autor considera su principal trabajo, "Vindicaciones de los derechos de la mujer". El autor plantea que Wollstonecraft piensa que la revolu- ción y sus principios de igualdad caían en contradicción cuando de las mujeres se trataba, ya que éstos solo incluían a los hombres. La llustración reproducía una construcción cultural propia del sistema aristocrático que se pretendía eliminar. Una de ellas era el concepto de subordinación, lo cual abarcaba, entre otros, a las mujeres. Perea concluye que estudiar a esta filósofa es pensar en los valores feministas que emergerán en el siglo XVIII y XIX.

Todos los capítulos cuentan con la bibliografía específica utilizada para contextualizar el mismo, además del uso de los libros y publicaciones hechos por las protagonistas de cada uno. Esto le da al trabajo un mayor respaldo académico digno de ser reconocida.

Cada capítulo contextualiza a las autoras en su época haciendo una descripción de las formas de pensar y actuar de la modernidad temprana. Otro aspecto destacable es que las enmarca dentro de su planteo como mujeres, defendiendo las posturas feministas que muchas hicieron en su época. El trabajo rescata del olvido a las filósofas de la periferia intelectual, distintas ya que pretendían salir de esa sumisión y sombra que las sociedades de su tiempo establecían sobre ellas.

\section{Notas}

' Doctora en Filosofía por la Universidad Autó noma de México (UNAM). Actualmente se desempeña como Directora del Departamento de Filosofía de la Universidad La Salle de Me

xico. Es especialista en Filosofía de la Modernidad.

${ }^{2}$ Doctor en Filosofía por la Universidad Autónoma de México (UNAM). Su especialidad reflejada en varios artículos y libros en colaboración, se dedican a la historia de la Filosofía, principalmente en el Medioevo, el Renacimiento, la Modernidad Temprana y el siglo XIX. Pueden consultarse más datos en: https://leoneltoledo.wordpress.com.

${ }^{3}$ Laura BENÍTEZ, José Antonio ROBLES: Filósofas de la Modernidad temprana y la llustración, Biblioteca Digital de Humanidades, Dirección General del Área Académica de Humanidades, Universidad Veracruzana, p.15-16.

Alvaro García Universidad de Montevideo, Montevideo, Uruguay 